IP Periodica Polytechnica Civil Engineering

\author{
OnlineFirst (2015) paper 7674 \\ DOI: $10.3311 /$ PPci.7674 \\ Creative Commons Attribution (i)
}

RESEARCH ARTICLE

\section{Effectiveness of Microfine Portland Cement Grouting on the Strength and Permeability of Medium to Fine Sands}

\author{
Murat Mollamahmutoglu, Eyubhan Avci
}

Received 25-08-2014, revised 08-11-2014, accepted 30-01-2015

\begin{abstract}
The purpose of this research was to investigate the grout properties of microfine Portland cement whose specific surface area was greater than those of the same kind products frequently cited in the relevant literature. In this regard, viscosity, setting time and stability of microfine cement suspensions were initially studied. It was seen that the sedimentation and the setting time increased but the viscosity decreased as the water/cement $(W / C)$ ratio of microfine Portland cement suspensions increased. In addition, the penetrability of microfine Portland cement suspensions with different $W / C$ ratios into various graded medium-tofine sand specimens prepared at a relative density of $30 \%$ was tested under grouting pressures ranging from 0.25 to $0.5 \mathrm{MPa}$. It was observed that the penetrability of cement suspensions into the specimens was successful and increased as the W/C ratio increased. All grouted samples were kept in humidity room at a temperature of $20^{\circ} \mathrm{C}$ until testing time and subjected to permeability and unconfined compressive strength tests at different time intervals. The unconfined compressive strength decreased as the $W / C$ ratio as well as the fine content of sand increased. Permeability tests conducted on grouted specimens with a period of two months revealed that they were impermeable.
\end{abstract}

\section{Keywords}

Microfine cement $\cdot$ Stability $\cdot$ Groutability $\cdot$ Strength $\cdot$ Permeability

\section{Murat Mollamahmutoglu}

Faculty of Engineering, Gazi University, Ankara, Turkey

Eyubhan Avci

Vocational School, Hitit University, Corum, Turkey

e-mail: eyubhanavci@mynet.com

\section{Introduction}

Suspension grouts are widely used as a ground improvement technique all over the world. It involves the injection of suitable suspension and/or solution into soil and rock to either reduce the permeability or improve the mechanical properties. The grouting characteristics of microfine cement grouts have been a major research subject for the last two decades since they are regarded as an alternative to chemical grouts to some extent. One of the main challenges in the utilization of microfine cement is its grain size distribution, which is quite finer than that of Ordinary Portland Cement (OPC). Microfine cement grouts have also better flow properties and bleed characteristics than OPC grouts [1-3]. In addition, the application of some chemical grouts is limited because of their high cost, permanence and toxicity. The first microfine cement available commercially was MC-500, manufactured by Onoda Cement Corporation in Japan [4]. Later, much finer cement products are being produced and therefore the subject is still continuing to be a study of interest. Considerable amount of studies have been conducted by researchers to document the engineering properties (i.e., unconfined compressive strength and permeability) of microfine cement grouted sand. However, variability in published results have been observed due to the type of cement, sand density, and grout mixing procedures [5].

The main goal of this experimental study was to evaluate such grouting properties as viscosity, setting time and stability of microfine Portland cement with high specific surface area in comparison with the same kind products. The penetrability of microfine Portland cement suspensions into medium to fine sand specimens at a relative density of $30 \%$ was studied. The reason for adopting a relative density of 30 percent for experimental study was that liquefaction occurs principally in saturated sands and/or silty sands having a relative density less than $50 \%$.

The strength and the permeability of successfully permeated sand samples were evaluated thus compensating for the lack of data especially with respect to fine content effect on the strength as well as the permeability of microfine cement grouted sands. 


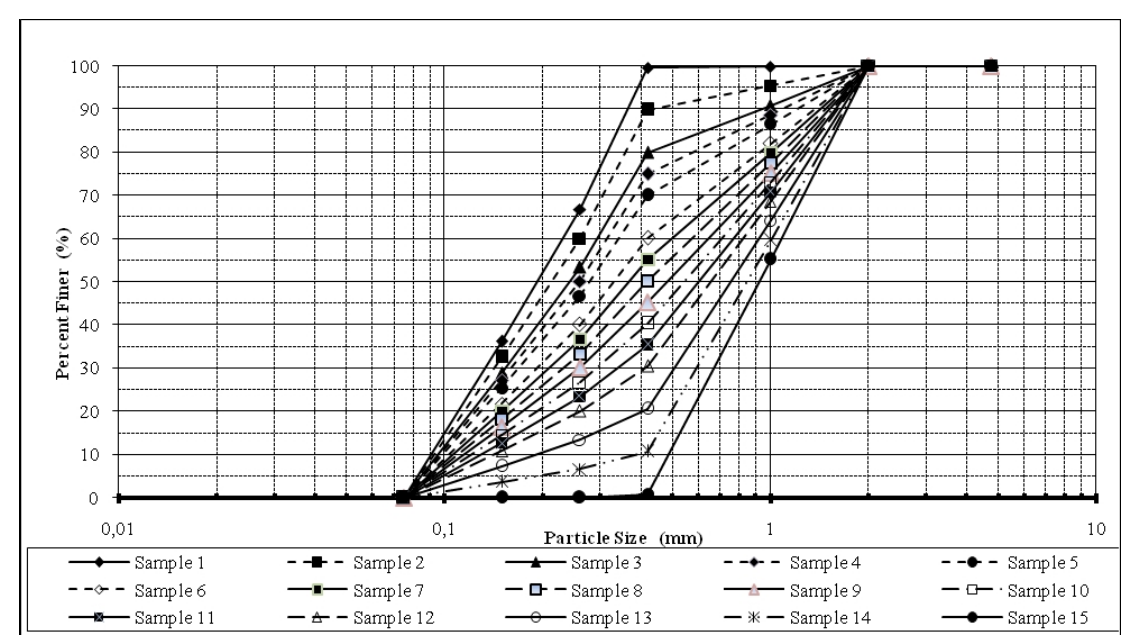

Fig. 1. Particle size distribution of sand specimens

Tab. 1. Sand samples

\begin{tabular}{|c|c|c|c|c|c|c|c|}
\hline \multirow{2}{*}{ Sample Name } & \multicolumn{2}{|c|}{ Particle size content \% } & \multirow{2}{*}{$\begin{array}{c}\gamma_{d r y(\max )} \\
\mathrm{kN} / \mathrm{m}^{3}\end{array}$} & \multirow{2}{*}{$\begin{array}{c}\gamma_{d r y(\min )} \\
\mathrm{kN} / \mathrm{m}^{3}\end{array}$} & \multirow{2}{*}{$e_{\max }$} & \multirow{2}{*}{$e_{\min }$} & \multirow{2}{*}{$k(\mathrm{~cm} / \mathrm{s})$} \\
\hline & Fine & Medium & & & & & \\
\hline 1 & 100 & 0 & 15.80 & 12.60 & 1.14 & 0.71 & $3.22 \times 10^{-3}$ \\
\hline 2 & 90 & 10 & 15.70 & 12.60 & 1.14 & 0.71 & $8.85 \times 10^{-3}$ \\
\hline 3 & 80 & 20 & 15.70 & 12.70 & 1.13 & 0.72 & $3.36 \times 10^{-2}$ \\
\hline 4 & 75 & 25 & 15.70 & 12.70 & 1.13 & 0.72 & $4.05 \times 10^{-2}$ \\
\hline 5 & 70 & 30 & 15.70 & 12.70 & 1.13 & 0.72 & $4.79 \times 10^{-2}$ \\
\hline 6 & 60 & 40 & 15.60 & 12.70 & 1.12 & 0.73 & $6.22 \times 10^{-2}$ \\
\hline 7 & 55 & 45 & 15.60 & 12.70 & 1.12 & 0.73 & $6.81 \times 10^{-2}$ \\
\hline 8 & 50 & 50 & 15.60 & 12.80 & 1.11 & 0.73 & $7.65 \times 10^{-2}$ \\
\hline 9 & 45 & 55 & 15.60 & 12.80 & 1.11 & 0.73 & $8.15 \times 10^{-2}$ \\
\hline 10 & 40 & 60 & 15.60 & 12.80 & 1.11 & 0.73 & $9.08 \times 10^{-2}$ \\
\hline 11 & 35 & 65 & 15.50 & 12.80 & 1.11 & 0.73 & $9.98 \times 10^{-2}$ \\
\hline 12 & 30 & 70 & 15.50 & 12.80 & 1.10 & 0.74 & $1.05 \times 10^{-1}$ \\
\hline 13 & 20 & 80 & 15.50 & 12.90 & 1.10 & 0.74 & $1.19 \times 10^{-1}$ \\
\hline 14 & 10 & 90 & 15.50 & 12.90 & 1.09 & 0.74 & $1.34 \times 10^{-1}$ \\
\hline 15 & 0 & 100 & 15.40 & 13.00 & 1.08 & 0.75 & $1.48 \times 10^{-1}$ \\
\hline
\end{tabular}

Note $: \gamma_{d r y(\max )}:$ maximum dry density $; \gamma_{d r y(\min )}:$ minimum dry density ; $e_{\max }:$ maximum void ratio; $e_{\min }:$ minimum void ratio; $\mathrm{k}$ : coefficient of permeability

\section{Material and methods}

\subsection{Index Properties of Sand}

Quartz sand procured from Kızılırmak River running near Çorum province in Turkey was used in this experimental study. The specific gravity of the sand was determined to be 2.61 in accordance with ASTM D 854-02 [6]. The sand used was first divided into two different subgroups. Each subgroup was obtained using two sets of sieves in such a way that sand specimen was first passed through the upper sieve $(0.63 \mathrm{~mm})$ and those retained on the lower sieve of $0.2 \mathrm{~mm}$ mesh size were collected and named as medium sand. Then the other subgroup was passed through a set of sieves $(0.2 \mathrm{~mm}-0.063 \mathrm{~mm})$. The amount of sand particles retained on the lower sieve of $0.063 \mathrm{~mm}$ mesh size was collected and named as fine sand [7]. To broaden the range of various graded sand samples, the subgroups were mechanically mixed with each other at different percentages by dry mass. In this way, 15 different graded sand samples were formed (Table 11) and their particle size distribution curves were shown in Fig. 1
In order to produce various graded sand specimens at a relative density of 30 percent, the maximum and the minimum dry unit weights of the samples were determined (Table 1) according to ASTM D 4253-00 [8] and ASTM D 4254-00 [9] standards respectively

\subsection{Properties of Microfine Cement}

Cement is characterized as a microfine cement if the specific surface area is greater than $8000 \mathrm{~cm}^{2} / \mathrm{g}$ and the corresponding $95 \%$ finer $\left(\mathrm{D}_{95}\right)$ particle diameter is smaller than $20 \mu \mathrm{m}[10]$. In this context, the surface area of microfine cement (Ultrafin 12) is $22.000 \mathrm{~cm}^{2} / \mathrm{g}$ and 95 percent of its particles is finer than $12 \mu \mathrm{m}$. Moreover, it is purely Portland cement-based product. The particle size distribution of microfine cement was determined by particle sizing instrument. It uses the technique of laser diffraction to measure the size of particles. It does this by measuring the intensity of light scattered as a laser beam passes through a dispersed particulate sample. This data was then analyzed to calculate the size of the particles which created the scattering 
Tab. 2. Physical properties of Ultrafin 12 together with the same kind of other microfine cements

\begin{tabular}{c|cccc}
\hline & Ultrafin 12 & MC 300 & Rheocem 900 & MC 500 \\
\hline Composition & Portland & Portland & Portland & Portland \\
\hline Manufacturer & $\begin{array}{c}\text { Heidelberg Cement } \\
\text { AG }\end{array}$ & $\begin{array}{c}\text { Onoda Cement } \\
\text { Corporation }\end{array}$ & $\begin{array}{c}\text { BASF The } \\
\text { chemical company }\end{array}$ & $\begin{array}{c}\text { Onoda Cement } \\
\text { Corporation }\end{array}$ \\
\hline D50 $(\mu \mathrm{m})$ & 3.1 & 2.8 & 3.7 & 4.1 \\
\hline D95 $(\mu \mathrm{m})$ & 10 & 11.2 & 11.1 & 9.9 \\
\hline Specific Gravity & 3.1 & 3.15 & - & 3.1 \\
\hline Fineness $\left(\mathrm{cm}^{2} / \mathrm{g}\right)$ & 22.000 & 10.000 & 9.000 & 9.000 \\
\hline
\end{tabular}

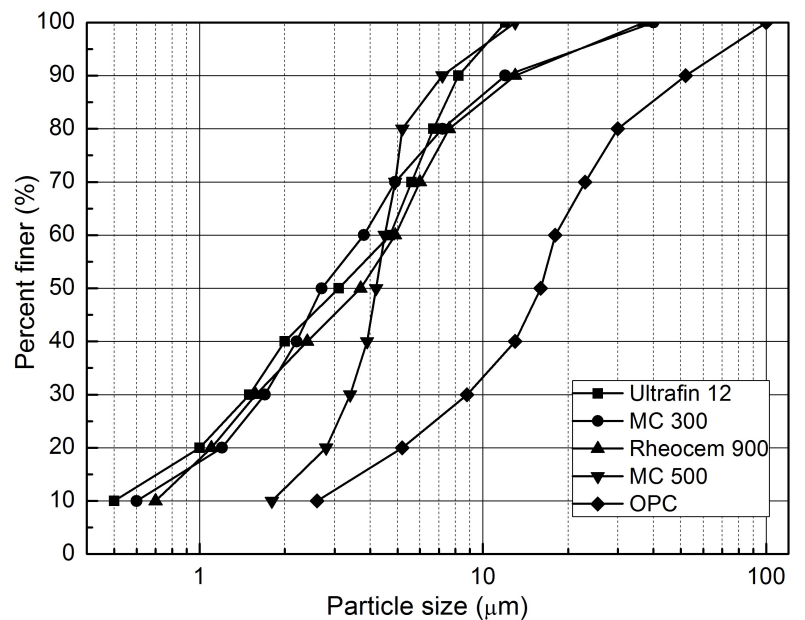

Fig. 2. Particle size distributions of Ultrafin 12 together with the same kind of other microfine cements and that of OPC

pattern. The particle size distributions of Ultrafin 12 together with the same kind of other microfine cements and that of OPC were given in Fig 2 In addition, some of their physical properties were also given in Table 2. As noticed, Ultrafin 12 has finer particle sizes and specific surface area when compared with others (Table 2). These findings indicated that Ultrafin 12 would probably have better penetrability than those given in Table 2

\subsection{Injection}

The injection test apparatus consisted of a manometer, 5 molds for compressive strength tests, 3 molds for permeability, a grout tank with propeller and relevant connections. Molds were $53.60 \mathrm{~mm}$ in diameter and $150 \mathrm{~mm}$ in length. They were designed in a way that the height to diameter ratio of 2.0 could be obtained for compressive strength tests. The details of test apparatus were shown in Fig 3 .

The inner surface of the molds was lightly lubricated to eliminate sample disturbance upon removal from molds after injection. To prepare the specimens, a coarse sand layer of about $20 \mathrm{~mm}$ in thickness was first placed at the bottom of the molds to distribute the suspension evenly into the sample. Sand samples were then poured into molds in three equal layers. Each layer was compacted using a wooden tamp to achieve the desired relative density before placing the next layer. For 30\% relative density of sand specimens, the initial void ratio $\left(e_{o}\right)$ was calculated from the empirical relation of relative density since the maximum and minimum void ratios were determined by experimental studies as mentioned before. Thereafter, based on initial void ratio and specific gravity of sand, the relevant unit weight was estimated and the required mass of sand was calculated. From all these quantities, the relative density for each layer was checked.

After placing the specimen at the achievable relative density, a coarse sand layer of about $20 \mathrm{~mm}$ in thickness was also placed at the top of the molds (The course layers at the top and at the bottom were cut off from the grouted samples before strength tests). Then the top and bottom end-plates of the molds were clamped using tie rods (Fig 3). Finally, samples were filled with water. The top and bottom ends were sealed and kept aside until injection. Before grouting operation, the sand specimens were saturated by the upward flow of tap water through the bottom under $0.020 \mathrm{MPa}$ pressure. Water was allowed to flow through the specimens until no air bubbles emerged from the outlet at the top of the samples. At that time the permeability of the sand was calculated and water flow was continued until a constant permeability value was obtained; such a condition was assumed to indicate saturation of the sand [2]. The permeability values of sand specimens prepared for grouting were given in Table 1.

The microfine cement and water were mixed thoroughly in a container by means of high-speed propeller-type mixer at $3,000 \mathrm{rpm}$ for about three minutes. The grout was then transferred to the grouting tank where it was agitated at a speed of $150 \mathrm{rpm}$ to avoid the sedimentation of cement grout during injection and was finally injected into the sand specimen in molds as agitation went on. No dispersive agent was used in grouts. The grouting pressure used ranged from 0.25 to $0.50 \mathrm{MPa}$. The grout pressure was provided with air compressor and monitored by manometer mounted on it.

\subsection{Rheological Properties of Suspensions}

Stability tests were performed with reference to ASTM C 940-98a [11]. Suspensions having different $W / C$ ratios were placed in a $1,000 \mathrm{ml}$ graduated cylinder and the volume of bleed liquid on top of grout to the total volume of the suspension at the end of 120 minutes were recorded (Table 3). Table 3 indicated that the bleedings of grouts with $W / C$ ratios of $0.8,1.0$, 1.2 and 1.5 were less than five percent at the end of two hours and therefore they were considered to be stable. The initial and 


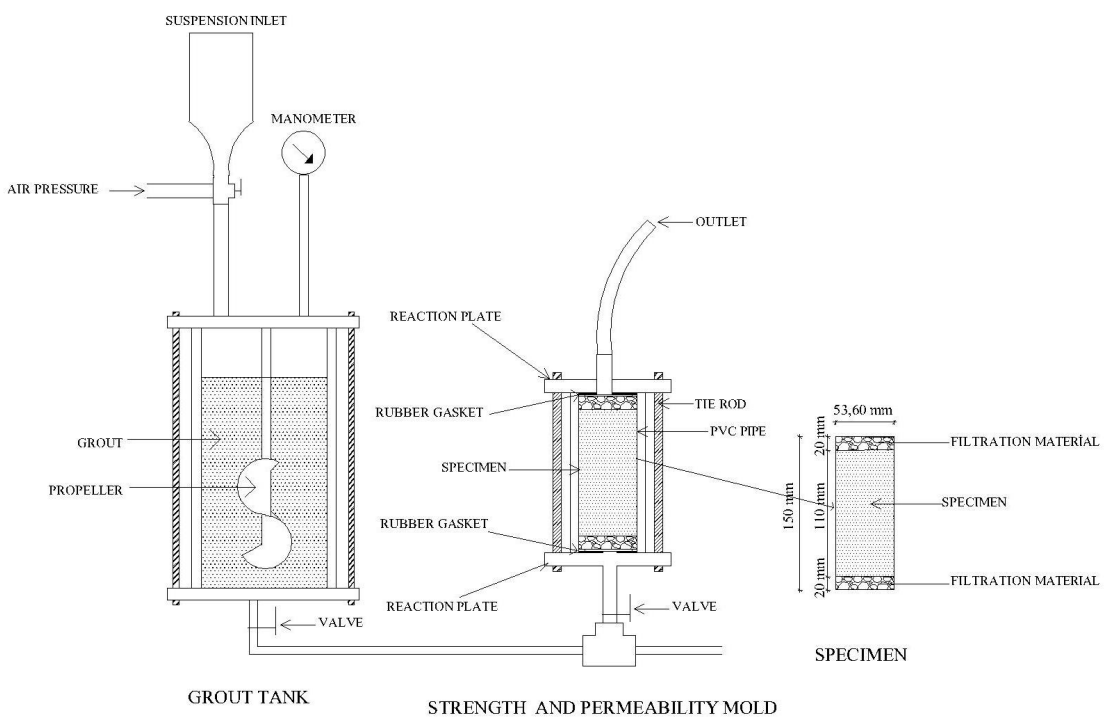

Fig. 3. Technical details of the grouting test apparatus

Tab. 3. Results of stability, setting time, and viscosity tests

\begin{tabular}{|c|c|c|c|}
\hline & \multirow{2}{*}{$W / C$} & \multicolumn{2}{|c|}{ Microfine cement } \\
\hline & & Bleeding (\%) & Explanation \\
\hline \multirow{9}{*}{ Sedimentation } & 0.8 & 0.00 & Stable \\
\hline & 1.0 & 0.00 & Stable \\
\hline & 1.2 & 1.33 & Stable \\
\hline & 1.5 & 2.67 & Stable \\
\hline & 2.0 & 8.15 & Not stable \\
\hline & 2.5 & 23.15 & Not stable \\
\hline & 3.0 & 29.17 & Not stable \\
\hline & 3.5 & 35.44 & Not stable \\
\hline & 4.0 & 40.00 & Not stable \\
\hline \multirow{10}{*}{ Setting Time } & $W / C$ & Initial Setting Time (min.) & Final Setting Time (min.) \\
\hline & 0.8 & 360 & 440 \\
\hline & 1.0 & 370 & 467 \\
\hline & 1.2 & 433 & 693 \\
\hline & 1.5 & 455 & 930 \\
\hline & *2.0 & 680 & 4058 \\
\hline & *2.5 & 1625 & 22290 \\
\hline & *3.0 & 2080 & 36025 (end of test) \\
\hline & *3.5 & 8505 & 36020 (end of test) \\
\hline & *4.0 & 9700 & end of test \\
\hline \multirow{10}{*}{ Viscosity } & $W / C$ & Flow time (sec.) & Viscosity $(\mathrm{cP})$ \\
\hline & 0.8 & 52 & 45.05 \\
\hline & 1.0 & 41 & 24.50 \\
\hline & 1.2 & 37 & 15.99 \\
\hline & 1.5 & 34 & 8.33 \\
\hline & 2.0 & 33 & 2.61 \\
\hline & 2.5 & 33 & 2.26 \\
\hline & 3.0 & 32 & 1.14 \\
\hline & 3.5 & 32 & 1.08 \\
\hline & 4.0 & 31 & 1.02 \\
\hline
\end{tabular}

*Setting time is prolonged due to the decreasing quantity of cement in suspension 
Tab. 4. The groutability test results of microfine cement suspensions

\begin{tabular}{|c|c|c|c|c|}
\hline \multirow{2}{*}{ Sample Name } & \multicolumn{2}{|c|}{ Particle size (\%) } & \multirow[t]{2}{*}{$W / C$} & \multirow{2}{*}{$\begin{array}{c}\text { Grouting } \\
\text { performance }\end{array}$} \\
\hline & Fine & Medium & & \\
\hline 12 & 30 & 70 & 0.8 & Successful \\
\hline 10 & 40 & 60 & 0.8 & Successful \\
\hline 8 & 50 & 50 & 0.8 & Successful \\
\hline 6 & 60 & 40 & 0.8 & Successful \\
\hline 5 & 70 & 30 & 0.8 & Unsuccessful \\
\hline 15 & 0 & 100 & 1.0 & Successful \\
\hline 12 & 30 & 70 & 1.0 & Successful \\
\hline 11 & 35 & 65 & 1.0 & Successful \\
\hline 10 & 40 & 60 & 1.0 & Successful \\
\hline 9 & 45 & 55 & 1.0 & Successful \\
\hline 8 & 50 & 50 & 1.0 & Successful \\
\hline 7 & 55 & 45 & 1.0 & Successful \\
\hline 6 & 60 & 40 & 1.0 & Successful \\
\hline 5 & 70 & 30 & 1.0 & Successful \\
\hline 4 & 75 & 25 & 1.0 & Unsuccessful \\
\hline 3 & 80 & 20 & 1.0 & Unsuccessful \\
\hline 1 & 100 & 0 & 1.0 & Unsuccessful \\
\hline 6 & 60 & 40 & 1.2 & Successful \\
\hline 5 & 70 & 30 & 1.2 & Successful \\
\hline 3 & 80 & 20 & 1.2 & Successful \\
\hline 2 & 90 & 10 & 1.2 & Unsuccessful \\
\hline 1 & 100 & 0 & 1.2 & Unsuccessful \\
\hline 6 & 60 & 40 & 1.5 & Successful \\
\hline 5 & 70 & 30 & 1.5 & Successful \\
\hline 3 & 80 & 20 & 1.5 & Successful \\
\hline 2 & 90 & 10 & 1.5 & Successful \\
\hline 1 & 100 & 0 & 1.5 & Successful \\
\hline
\end{tabular}

Tab. 5. Comparison of the test results with Burwell's criteria (For $W / C=1.5$ )

$\left(D_{85}\right)$ grout solid $=0.0072 \mathrm{~mm}$

$\left(D_{95}\right)$ grout solid $=0.0100 \mathrm{~mm}$

\begin{tabular}{|c|c|c|c|c|c|c|c|c|}
\hline \multirow{3}{*}{ Sample No } & \multicolumn{3}{|c|}{$\left(D_{85}\right)$ grout solid $=0.0072 \mathrm{~mm}$} & \multicolumn{3}{|c|}{$\left(D_{95}\right)$ grout solid $=0.0100 \mathrm{~mm}$} & \multirow{3}{*}{$\begin{array}{c}\text { Burwell's } \\
\text { criteria }\end{array}$} & \multirow{3}{*}{ Test Results } \\
\hline & \multicolumn{2}{|c|}{ Grain size percent } & \multirow[t]{2}{*}{$\begin{array}{l}\left(D_{10}\right) \text { soil } \\
(\mathrm{mm})\end{array}$} & \multirow[t]{2}{*}{$\begin{array}{c}\left(D_{15}\right) \text { soil } \\
(\mathrm{mm})\end{array}$} & \multirow{2}{*}{$\begin{array}{c}N=\left(D_{15}\right) \text { soil } \\
/\left(D_{85}\right) \text { grout } \\
\text { solid } \mathrm{N}>25\end{array}$} & \multirow{2}{*}{$\begin{array}{c}N c=\left(D_{10}\right) \\
\text { soil / }\left(D_{95}\right) \\
\text { grout solid } \\
\quad \mathrm{N}>11\end{array}$} & & \\
\hline & Fine & Medium & & & & & & \\
\hline 15 & 0 & 100 & 0.50 & 0.52 & 72 & 50 & Successful & Successful \\
\hline 14 & 10 & 90 & 0.46 & 0.48 & 66 & 46 & Successful & Successful \\
\hline 13 & 20 & 80 & 0.42 & 0.44 & 61 & 42 & Successful & Successful \\
\hline 12 & 30 & 70 & 0.38 & 0.39 & 55 & 38 & Successful & Successful \\
\hline 11 & 35 & 65 & 0.36 & 0.37 & 52 & 36 & Successful & Successful \\
\hline 10 & 40 & 60 & 0.34 & 0.35 & 49 & 34 & Successful & Successful \\
\hline 9 & 45 & 55 & 0.32 & 0.33 & 46 & 32 & Successful & Successful \\
\hline 8 & 50 & 50 & 0.30 & 0.31 & 43 & 30 & Successful & Successful \\
\hline 7 & 55 & 45 & 0.27 & 0.29 & 40 & 27 & Successful & Successful \\
\hline 6 & 60 & 40 & 0.25 & 0.27 & 37 & 25 & Successful & Successful \\
\hline 5 & 70 & 30 & 0.21 & 0.23 & 31 & 21 & Successful & Successful \\
\hline 4 & 75 & 25 & 0.19 & 0.21 & 28 & 19 & Successful & Successful \\
\hline 3 & 80 & 20 & 0.17 & 0.18 & 26 & 17 & Successful & Successful \\
\hline 2 & 90 & 10 & 0.13 & 0.14 & 20 & 13 & Successful & Successful \\
\hline 1 & 100 & 0 & 0.12 & 0.13 & 18 & 12 & Successful & Successful \\
\hline
\end{tabular}


final setting times of microfine cement suspensions given in Table 3 were determined according to ASTM C 191-04b [12]. It was seen that as $W / C$ ratio increased the setting times increased too. Flow times obtained according to ASTM C 939-02 [13], and the viscosities from Lombardi's approach were given in Table 3. Lombardi [14] devised a cohesion meter that can be used in conjunction with the Marsh viscosity to determine the apparent viscosity of the grout. Moreover, increase in $W / C$ ratio decreased the viscosities of microfine cement suspensions.

\section{Results and Discussion}

\subsection{Penetrability}

The ability of a grout to penetrate porous material is a function of the rheological properties of the grout suspension and the physical characteristics of the cement, as well as the physical characteristics of the soil [15-17].

The penetrability of the Microfine cement suspensions with different $W / C$ ratios into various graded fine-to-medium sand specimens was investigated. Various graded sand samples at a constant relative density of 30 percent were injected with $W / C$ ratios of $0.8,1.0,1.2$ and 1.5 and the results were given in Table 4 The penetration of suspension with $W / C$ ratio of 0.8 was unsuccessful for specimen 5 where the fine sand content reached $70 \%$. Similarly, the penetration of suspension with $W / C$ ratio of 1.0 into specimens 4,3 and 1 where the fine sand content reached $75 \%$ and the penetration of suspension with $W / C$ ratio of 1.2 into specimens 2 and 1 where the fine sand content reached $90 \%$ were unsuccessful. Moreover, the penetration of suspension with $W / C$ ratio of 1.5 was successful for all specimens including $100 \%$ percent fine sand as shown in Table 4 With the increase of fine sand content, the penetration performance of cement suspensions decreased but with the increase of $W / C$ ratio, the penetration performance of cement suspensions increased. Similar findings were also reported by Zebovitz [2], Eklund and Stille [17] and Markou et al. [18].

The results of the penetration are characterized as "successful" when the predetermined quantity of grout (two void volumes of the sand specimen) are injected, as "unsuccessful" when the grout penetration is less than the length of the sand specimens $(150 \mathrm{~mm})$ or particles are filtered from the grout [19].

Injection test results were also evaluated in accordance with Burwell criteria and results were given in Table 5 . As seen from the table, test results and the Burwell [20] criteria confirmed each other only for the $W / C$ ratio of 1.5 . Burwell' criteria estimated the groutibility of cementitious grouts in some cases but failed in some others. Therefore, they cannot be considered as a universal criteria [2, 3]. This behavior may be attributed to the fact that Burwell criteria are based solely on grain sizes of grout and soil and do not take into consideration such factors as $W / C$ ratio and therefore viscosity which have a considerable effect on penetrability of grouts.

\subsection{Strength of Grouted Samples}

After grouting, the specimens were kept in molds until the grout sets. Then the specimens were removed from the molds and preserved in a humid room at a temperature of $20^{\circ} \mathrm{C}$ until testing time. The grouted samples $(53.60 \mathrm{~mm}$ in diameter and $110 \mathrm{~mm}$ in length) were tested for unconfined compressive strength according to ASTM C 4219-02 [21]. To see the aging effect on the strength of grouted specimens, the specimens were tested at the end of $1^{s t}, 3^{r d}, 7^{\text {th }}, 14^{\text {th }}, 28^{\text {th }}$, and $56^{\text {th }}$ days and the test results were given in Table 6. The results showed that the unconfined compressive strength increased with curing period and most of the strength (about more than $80 \%$ ) gained at the end of 28 days. In addition, the strength of grouted specimens decreased with the increase of fine percentage of sand specimens and $W / C$ ratio. This finding seems to contradict earlier ones reported by Zebovitz et al. [2], Schwarz and Krizek [15] and Dano et al. [22]. The main reason might be due to the fact that fine particles fill in the voids formed by coarser particles thus reducing the efficiency of grout penetration into the sand specimens and causing weak bonds between particles. The other reasons may be as follows:

- $W / C$ ratio of grout,

- Relative density of sand specimen,

- Penetrability of suspensions,

- Nature, shape and fineness of sand and cement particles and

- Grouting pressure.

\subsection{Permeability of Grouted Samples}

The permeability of grouted sand specimens was investigated by performing falling head permeability test under the gradient of 19 in accordance with ASTM C 5856-95 [23]. Since no flow of water was observed from microfine Portland cement grouted sand specimen for two months, they were considered to be impermeable. Some permeability values of grouted sand samples such as $10^{-4} \mathrm{~m} / \mathrm{s}$ and $10^{-6} \mathrm{~m} / \mathrm{s}$ were reported by Zebovitz et al. [2] and Schwarz and Chirumalla [24] respectively. But, the test conditions were not comparable. There are some differences arising from such factors as $W / C$ ratio of grout used, fineness of cement and therefore efficiency of grout penetration into sand specimens, the duration and the pressures under which the permeability tests were carried out.

\section{Conclusions}

The main conclusions drawn from this study were as follows:

- The microfine Portland cement suspensions with a range of $W / C$ ratios of $0.8,1.0,1.2$ and 1.5 had a good bleeding and flow characteristics.

- Increase in $W / C$ ratio increased the penetrability of microfine cement suspensions into various graded medium to fine sand. The penetrability of microfine cement suspensions decreased 
Tab. 6. Unconfined compressive test results

\begin{tabular}{|c|c|c|c|c|c|c|c|c|c|}
\hline \multirow{2}{*}{$\begin{array}{l}\text { Sample } \\
\text { Name }\end{array}$} & \multicolumn{2}{|c|}{ Particle size (\%) } & \multirow{2}{*}{$W / C$} & \multicolumn{6}{|c|}{ Unconfined compressive strength, $\mathrm{MPa}$} \\
\hline & Fine & Medium & & $1^{s t}$ day & $3^{\text {rd }}$ day & $7^{\text {th }}$ day & $14^{\text {th }}$ day & $28^{\text {th }}$ day & $56^{\text {th }}$ day \\
\hline 12 & 30 & 70 & 0.8 & 0.61 & 1.21 & 3.05 & 5.32 & 10.83 & 12.50 \\
\hline 10 & 40 & 60 & 0.8 & 0.53 & 1.04 & 2.58 & 4.58 & 9.21 & 10.50 \\
\hline 8 & 50 & 50 & 0.8 & 0.49 & 0.96 & 2.41 & 4.28 & 8.55 & 9.70 \\
\hline 6 & 60 & 40 & 0.8 & 0.41 & 0.81 & 2.02 & 3.86 & 7.28 & 8.50 \\
\hline 15 & 0 & 100 & 1.0 & 0.58 & 1.16 & 2.90 & 5.08 & 10.26 & 11.80 \\
\hline 12 & 30 & 70 & 1.0 & 0.52 & 1.12 & 2.79 & 4.98 & 10.02 & 11.60 \\
\hline 11 & 35 & 65 & 1.0 & 0.49 & 1.00 & 2.51 & 4.29 & 8.72 & 10.20 \\
\hline 10 & 40 & 60 & 1.0 & 0.47 & 0.95 & 2.38 & 4.21 & 8.55 & 9.80 \\
\hline 9 & 45 & 55 & 1.0 & 0.45 & 0.91 & 2.27 & 4.02 & 8.22 & 9.50 \\
\hline 8 & 50 & 50 & 1.0 & 0.43 & 0.86 & 2.16 & 3.85 & 7.89 & 9.20 \\
\hline 7 & 55 & 45 & 1.0 & 0.41 & 0.81 & 2.03 & 3.61 & 7.35 & 8.60 \\
\hline 6 & 60 & 40 & 1.0 & 0.37 & 0.77 & 1.92 & 3.48 & 7.02 & 8.20 \\
\hline 5 & 70 & 30 & 1.0 & 0.33 & 0.69 & 1.73 & 3.22 & 6.68 & 7.80 \\
\hline 6 & 60 & 40 & 1.2 & 0.23 & 0.45 & 1.16 & 2.05 & 4.13 & 4.75 \\
\hline 5 & 70 & 30 & 1.2 & 0.18 & 0.34 & 0.84 & 1.49 & 3.00 & 3.45 \\
\hline 3 & 80 & 20 & 1.2 & 0.15 & 0.27 & 0.70 & 1.23 & 2.48 & 2.85 \\
\hline 6 & 60 & 40 & 1.5 & 0.16 & 0.31 & 0.76 & 1.32 & 2.71 & 3.10 \\
\hline 5 & 70 & 30 & 1.5 & 0.15 & 0.28 & 0.73 & 1.22 & 2.61 & 2.98 \\
\hline 3 & 80 & 20 & 1.5 & 0.14 & 0.26 & 0.65 & 1.19 & 2.41 & 2.71 \\
\hline 2 & 90 & 10 & 1.5 & 0.11 & 0.25 & 0.62 & 1.05 & 2.28 & 2.56 \\
\hline 1 & 100 & 0 & 1.5 & 0.10 & 0.23 & 0.57 & 0.99 & 2.11 & 2.30 \\
\hline
\end{tabular}

with the increasing content of fine particles in sand specimens. However, with the grout having $W / C$ ratio of $1.5, \% 100$ fine sand specimens were able to be successfully injected.

- Burwell criteria were not fully compatible with the injection test results. So they could not be used reliable as an indication of groutability of pure microfine Portland cement grouts.

- The unconfined compressive strength of grouted sand specimens increased with curing period but increase in $W / C$ ratio decreased their unconfined compressive strength. Furthermore, fine content increase in sand specimens decreased their unconfined compressive strength too.

- Specimens grouted with microfine Portland cement suspensions were subjected to falling head permeability tests for two months during which no flow of water was observed and therefore they were considered to be impermeable.

\section{References}

1 Littlejohn GS, Design of cement based grouts, Grouting in Geotechnical Engineering, ASCE, 1(1), (1982), 35-48.

2 Zebovitz S, Krizek RJ, Atmatzidis DK, Injection of fine sands with very fine cement grout, Journal of Geotechnical Engineering, 115(1), (1989), 1717-1733, DOI 10.1061/(ASCE)0733-9410(1989)115:12(1717)

3 De Paoli B, Bosco B, Granata R, Bruce DA, Fundamental observations on cement based grouts (2): Microfine cements and the Cemill1 process, In: Grouting, Soil Improvement and Geosynthetics, 1(1), (1992), 486-499.

4 Mollamahmutoglu M, Yilmaz Y, Kutlu I, Grouting performance of microfine cement and silica fume mix into sands, Journal ASTM International, 4(1), (2007), 1-7.
5 Abraham A, Effect of initial moisture state on the engineering properties of Microfine cement grouted sands, M.Sc. thesis, The University of Alabama in Huntsville; Huntsville, Alabama, USA, 2006.

6 ASTM D 854-02, Standard test method for specific gravity of soil solids by water pycnometer, Anual Book os ASTM standarts, ASTM; West Conshohocken, PA, USA, 2002.

7 Eurocode 7, Geotechnical design-Part II Ground investigation and testing, Eurocode; Brussel, 2008.

8 ASTM D 4253-00, Standard test method for maximum index density and unit weight of soils using a vibratory table, Annual Book of ASTM Standards, ASTM; West Conshohocken, PA, USA, 2002.

9 ASTM D 4254-00, Standard test method for minimum index density and unit weight of soils and calculation of relative density, Annual Book of ASTM Standards, ASTM; West Conshohocken, PA, USA, 2002.

10 BS EN 12715, Execution of special geotechnical work: Grouting. BritishAdopted European Standard, BS EN; London, UK, 2000.

11 ASTM C 940-98a, Standard test method for expansion and bleeding of freshly mixed grouts for preplaced aggregate concrete in the laboratory, Annual Book of ASTM, ASTM; West Conshohocken, PA, USA, 2002.

12 ASTM C 191-04b, Standard test method for flow of grout for preplacedaggregate concrete (flow cone method). Annual Book of ASTM Standards, ASTM; West Conshohocken, PA, USA, 2002.

13 ASTM C 939-02, Standard test method for flow of grout for preplacedaggregate concrete (flow cone method), Annual Book of ASTM Standards, ASTM; West Conshohocken, PA, USA, 2002.

14 Lombardi G, The role of cohesion in cement grouting of rock, 15th International congress on large dams (Lausanne, 1985), In:, pp. 235-260.

15 Schwarz LG, Krizek RJ, Effect of preparation technique on permeability and strength of cement-grouted sand, Geotechnical Testing Journal, 17(1), (1994), 434-443, DOI 10.1520/GTJ10304J

16 Mollamahmutoglu M, Treatment of medium to coarse-grained sands by fine-grained Portland cement (FGPC) as an alternative grouting material 
to silicate-ester grouts, Cement concrete aggregates journal, 25(1), (2003), 1235-1242, DOI $10.1520 / \mathrm{CCA} 10514 \mathrm{~J}$

17 Eklund D, Stille $\mathbf{H}$, Penetrability due to filtration tendency of cement-based grouts, Tunnelling Underground Space Technology, 23(1), (2008), 389-398, DOI $10.1016 /$ j.tust.2007.06.011

18 Markou I, Christodoulou D, Atmatzidis D, Effect of Sand Gradation on the Groutability of Cement Suspensions, Grouting and Deep Mixing, 1(1), (2012), 2003-2012, DOI $10.1061 / 9780784412350.0175$

19 Schwarz LG, Roles of rheology and chemical filtration on injectability of microfine cement grouts, PhD thesis, Northwestern University; Illinois, USA, 1997.

20 Burwell EB, Cement and clay grouting of foundations: practice of the corps of engineers, ASCE Soil Mechanics and Foundation Division, 84(1), (1958), $1-22$.

21 ASTM C 4219-02, Standard test method for unconfined compressive strength index of chemical-grouted, Annual Book of ASTM Standards, ASTM; West Conshohocken, PA, USA, 2002.

22 Dano C, Hilcher PY, Tailliez S, Engineering properties of grouted sands, Journal of Geotechnical Geoenviromental Engineering, 130(1), (2004), 328338.

23 ASTM C 5856-95, Standard test method for measurement of hydraulic conductivity of porous material using a rigid-wall, compaction-mold permeameter, Annual Book of ASTM, ASTM; West Conshohocken, PA, USA, 2002.

24 Schwarz LG, Chirumalla M, Effect of injection pressure on permeability and strength of microfine cement grouted sand, Grouting for ground improvement: innovative concepts and applications, ASCE, 1(1), (2007), 167-168, DOI $10.1061 / 40912(231) 2$ 